\title{
Quality control in immunocytochemistry: Experiences with the oestrogen receptor assay
}

\author{
F T Bosman, A F P M de Goeij, M Rousch
}

\begin{abstract}
Aims: To evaluate the feasibility of an interlaboratory quality control programme in immunohistochemistry. Methods: Several pathology laboratories were asked to carry out immunohistochemical oestrogen receptor staining on a set of freeze dried cryostat sections of breast cancer tissue. The sections and protocols for staining and semiquantitative scoring were mailed to the participating laboratories in two trials. The oestrogen receptor content of the breast cancer samples was determined by radioligand binding assay on the tumour cytosol.
\end{abstract}

Results: In the first trial 11 laboratories (response rate $60 \%$ ) participated. Eight $(73 \%)$ of the participants scored within a $95 \%$ confidence interval and all but one correctly classified the tumour as receptor positive. In the second trial all 20 participating laboratories (response rate $55 \%$ ) correctly scored one tumour sample as negative and 18 of them ( $90 \%$ of respondents) correctly classified the two other tumour samples as receptor positive. In a quantitative evaluation a histochemical score within $95 \%$ confidence interval limits was provided by eight $(40 \%)$ and 12 $(60 \%)$ of the participants.

Conclusions: Semiquantitative scoring of immunocytochemical staining is valuable for performing correlative interlaboratory studies, although this scoring protocol may not be required for diagnosis or prognosis. Significant interlaboratory variability exists, leading to qualitatively correct receptor classification in $100 \%$ of receptor negative and $80 \%$ of receptor positive cases, and quantitative agreement in only about half of the cases. The perceived variability is not caused by systematic differences in the choice of the immunocytochemical technique, or the mailing of freeze dried sections. Quality control programmes should be included in the standard procedures of each diagnostic immunohistochemistry laboratory.

Over the past decade immunocytochemistry has become essential in surgical pathology. The methodological requirements of reproducibility and specificity have been met with the hybridoma technique, which allows large quantities of monoclonal antibodies with selec- ted specificity to be produced, and the development of very sensitive second step reagents. As a consequence, almost every surgical pathology laboratory routinely uses immunocytochemistry on a daily basis. As recently indicated by Elias et al, ${ }^{1}$ however, an important source of variability in the performance of immunocytochemistry techniques is the variation among laboratories in tissue processing and histochemical procedures. This could be improved by standardisation, monitored by quality control programmes.

A typical example of an immunocytochemical test which requires such an approach is the evaluation of the oestrogen receptor content in breast cancer. About $60 \%$ of patients with an oestrogen receptor positive tumour will respond to some form of endocrine treatment; less than $10 \%$ of oestrogen receptor negative neoplasms respond. ${ }^{23}$ Expression of oestrogen receptor protein may also be regarded as a hallmark of a differentiated state, ${ }^{4}$ and many studies have shown that the prognosis in terms of disease free interval and survival in oestrogen receptor positive breast cancer is more favorable than that of oestrogen receptor negative breast cancer. ${ }^{5}$

In order for it to be clinically useful a reliable technique for oestrogen receptor determination is required. For two decades now, the standard steroid receptor assay has been the dextran coated charcoal (DCC) assay, used on cytosols of tumour tissue. Although reliable in principle, this ligand binding assay has been shown to lead to high inter- and intra-assay variability. Only the introduction of quality control programmes in the clinical chemistry laboratories in Europe, under the auspicies of the EORTC has led to a steroid receptor assay with reasonable widescale reproducibility. ${ }^{67}$ Replacement of this technique with an immunocytochemical assay, which would be preferable in view of the lesser quantity of tissue required, avoidance of the use of radiolabelled ligands, the possibility of locating the receptor protein specifically in tumour cells, and the ability to take tumour heterogeneity in receptor content into account have all been emphasised repeatedly..$^{8-10}$ The development of monoclonal antibodies has allowed steroid receptor assays based on antigen-antibody interactions to be introduced. ${ }^{11}$ It is clear, however, that immunocytochemical receptor determination can only be justified if: (a) the results of the immunocytochemical assay have been validated against those of the ligand binding assay; and (b) similar quality control programmes validate the intra- and inter- 
laboratory reproducibility of the technique. The first requirement has repeatedly been met. ${ }^{41213}$ This study was designed to test the feasibility of a quality control programme to meet the second requirement.

\section{Methods}

TISSUES AND MAILING OF THE SECTIONS

Samples of breast cancer tissue were snapfrozen in isopentane, cooled with dry ice. Tumours with a high, intermediate, or zero receptor content, as determined by radiochemical (DCC) assay on cytosol, were selected. Frozen sections $(6 \mu \mathrm{m})$ were cut on a cryostat microtome and mounted on gelatin chromealum coated slides. The slides were freeze dried and subsequently stored in a plastic airtight container over silica gel at room temperature. Each participating laboratory received four sections of each tumour and one section of a rabbit uterus which served as a receptor positive standard tissue. This was found to be an acceptable approach after it was shown that when kept absolutely dry, the sections could be kept at ambient temperatures for up to several weeks without deterioration of the immunoreactivity of oestrogen receptor protein.

In the first trial 11 pathology laboratories participated, 20 in the second trial. This represented a response rate of $60 \%$ and $55 \%$, respectively.

\section{IMMUNOHISTOCHEMISTRY}

Together with the mailing of the sections a staining protocol was provided that differed from the protocol included in the ERICA kit with respect to the working dilution of the antioestrogen receptor serum (1 in 4 instead of undiluted) and to the conditions of incubation with this antibody (overnight at $4^{\circ} \mathrm{C}$ instead of one hour at room temperature).

Before immunostaining, the sections were fixed ( 10 minutes at $4^{\circ} \mathrm{C}$ ) in picric acid-paraformaldehyde ${ }^{14}$ or in phosphate buffered $4 \%$

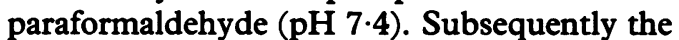
sections were rinsed (three times for five minutes at room temperature) in phosphate buffered saline (PBS). Before incubation the sections were exposed to $20 \%$ normal goat serum ( 15 minutes at room temperature). After blotting the section, the primary antibody (ERICA kit, kindly provided by Abbott Laboratories, Diagnostic Division, The Netherlands) was applied (diluted 1 in 4 in $1 \%$ bovine serum albumin in PBS) and the sections were incubated overnight in a humid chamber at $4^{\circ} \mathrm{C}$. Subsequently the sections were washed in PBS (three times for five minutes each) and incubated (30 minutes at room temperature) with goat-anti rat IgG (included in the ERICA kit or from Dako). After washing in PBS (three times for five minutes each) the sections were incubated (30 minutes at room temperature) with undiluted rat peroxidase-antiperoxidase complex (included in the ERICA kit or from Dako). After a final wash the immunoreactivity was visualised in a diaminobenzidine- $\mathrm{H}_{2} \mathrm{O}_{2}$ mixture (seven minutes at room temperature).
The sections were weakly counterstained in diluted haematoxylin and mounted in Entellan.

After the sections had been returned 11 of the 20 laboratories indicated that they had used the ERICA staining protocol, as outlined in the instructions supplied with the commercial kit (ERICA, Abbott Laboratories). One participant indicated that the protocol used was a local modification of the ERICA protocol. In the first pilot study two participants used the ERICA (Abbott) protocol.

\section{SEMIQUANTITATIVE ANALYSIS}

The stained sections were scored semiquantitatively, according to a modification of the scoring by McCarty et $a l,{ }^{15}$ as described earlier. ${ }^{16}$ The resulting histochemical score was obtained as follows:

$$
\text { Histochemical score }=\sum_{i=0}^{i=4} P(i) \times i
$$

where $\mathrm{i}=$ staining intensity, which may vary between 0 (no staining) and 4 (strongest staining), and $\mathrm{Pi}=$ percentage of stained tumour cell nuclei in category $i(0-100)$. The maximum attainable score is 400 by definition. For reliable visual scoring at least three cohorts of 100 tumour cells had to be scored in different high power fields (objective $\times 40$ ).

A receptor score of less than 35 was regarded as negative, based on earlier correlative studies ${ }^{16}$ between immunohistochemical receptor assays and radioligand binding assays. In these studies a cut-off value of 10 fmol oestrogen receptor/mg cytosol protein was used.

\section{OESTROGEN RECEPTOR ANALYSIS IN CYTOSOI} TISSUE

Oestrogen receptors were quantitated in tumour cytosols, prepared from a tumour sample directly adjacent to the sample used for

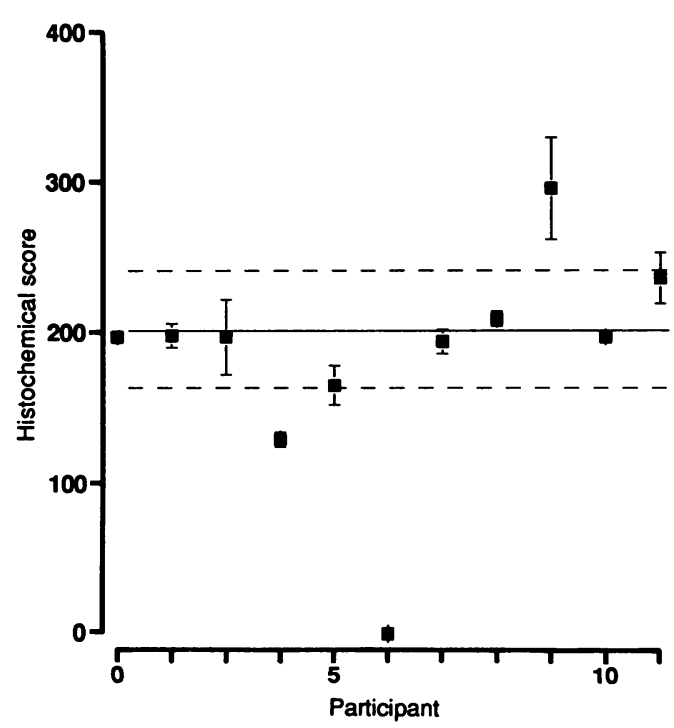

Figure 1 Semiquantitative immunohistochemical scoring of oestrogen receptor staining in cryostat sections from a human breast cancer sample distributed to 11 participating laboratories.

Scores of this first trial are presented as mean (SD) score calculated over three tumour cell cohorts. The dashed lines indicate the $95 \%$ confidence interval. Participants 4 and 5 used the Abbott protocol, the other laboratories used the Maastricht protocol. 
Table 1 Overall results (second test)

\begin{tabular}{|c|c|c|c|c|c|}
\hline \multirow[b]{2}{*}{ Sample } & \multicolumn{3}{|c|}{ Sections histochemical score ${ }^{\star}$} & \multicolumn{2}{|c|}{ Cytosol (fmol receptor/mg protein) } \\
\hline & $\begin{array}{l}\text { Total } \\
(n=20)\end{array}$ & $\begin{array}{l}\text { Maastricht } \\
(n=9)\end{array}$ & $\begin{array}{l}\text { Abbott } \\
(n=10)\end{array}$ & $D C C$ & $E I A$ \\
\hline $\begin{array}{l}1 \\
2 \\
3\end{array}$ & $\begin{array}{c}0 \\
145(67) \\
180(90)\end{array}$ & $\begin{array}{c}0 \\
163(64) \\
211(100)\end{array}$ & $\begin{array}{c}0 \\
148(74) \\
164(71)\end{array}$ & $\begin{array}{l}\text { Negative } \\
86 \\
103\end{array}$ & $\begin{array}{l}\text { Negative } \\
72 \\
128\end{array}$ \\
\hline
\end{tabular}

^Results include one laboratory that used a different staining protocol.

cryostat sectioning, using both radiochemical and immunochemical assays. The radiochemical receptor determination was done with a standard DCC assay according to the guidelines of the EORTC. ${ }^{17}$ The immunochemical oestrogen receptor assay was carried out with the enzyme immunoassay kit obtained from Abbott Laboratories according to the manufacturer's instructions. ${ }^{13}$ Both types of assay were performed in the laboratory of $\mathrm{Dr}$ Th Benraad of the University of Nijmegen, Academic Hospital, while participating in a steroid receptor assay quality control programme in Europe under the auspices of the EORTC. ${ }^{6}$

\section{Results}

In the first pilot study a single sample of breast cancer tissue was distributed to 11 pathology laboratories. The mean histochemical score (with standard deviations), calculated over the three scored tumour cell cohorts for each participant is shown in fig 1 . An average histochemical score of 210 was obtained on a sample with a cytosolic oestrogen receptor content of $519 \mathrm{fmol} / \mathrm{mg}$ protein. Eight of the 11 participants scored within a $95 \%$ confidence interval. All except one laboratory correctly classified the tumour as receptor positive.
The results of the immunohistochemical, radiochemical, and immunochemical oestrogen receptor assays of the second test are summarised in table 1. One tumour sample was oestrogen receptor negative by DCC assay as well as by enzyme immunoassay and was correctly scored negative by all laboratories. The other two tumour samples contained oestrogen receptor by both cytosol techniques and both immunohistochemistry protocols. On average, sample 3 yielded higher histochemical scores than sample 2, which corresponded with the results of the cytosol assay. The slides stained with the Maastricht staining protocol tended to show somewhat higher histochemical scores than those of the Abbott protocol, although the differences were not significant ( $p<0.0001$ ). One participant (15) scored significantly lower than the other using a modified staining protocol.

Striking differences in immunohistochemical results occurred (figs 2 and 3). Figure 2 shows photomicrographs of the two tumour samples, stained intensely in one laboratory (2A and $\mathrm{C}$ ) and only weakly in another (2B and D). This is quantitatively represented in fig 3 , which shows the plots of the histochemical scores. For sample 2 , the histochemical scores varied between 0 and 280 (fig $3 \mathrm{~A}$ ) and for sample 3 between 10 and 330 (fig 3B). Table 2 shows that
Figure 2 Illustration of immunohistochemical staining of human breast cancer samples by different pathology laboratories. $(A)$ and $(C)$ : laboratory 1 , samples 2 and $3 ;(B)$ and $(D)$ : laboratory 2 , samples 2 and 3.

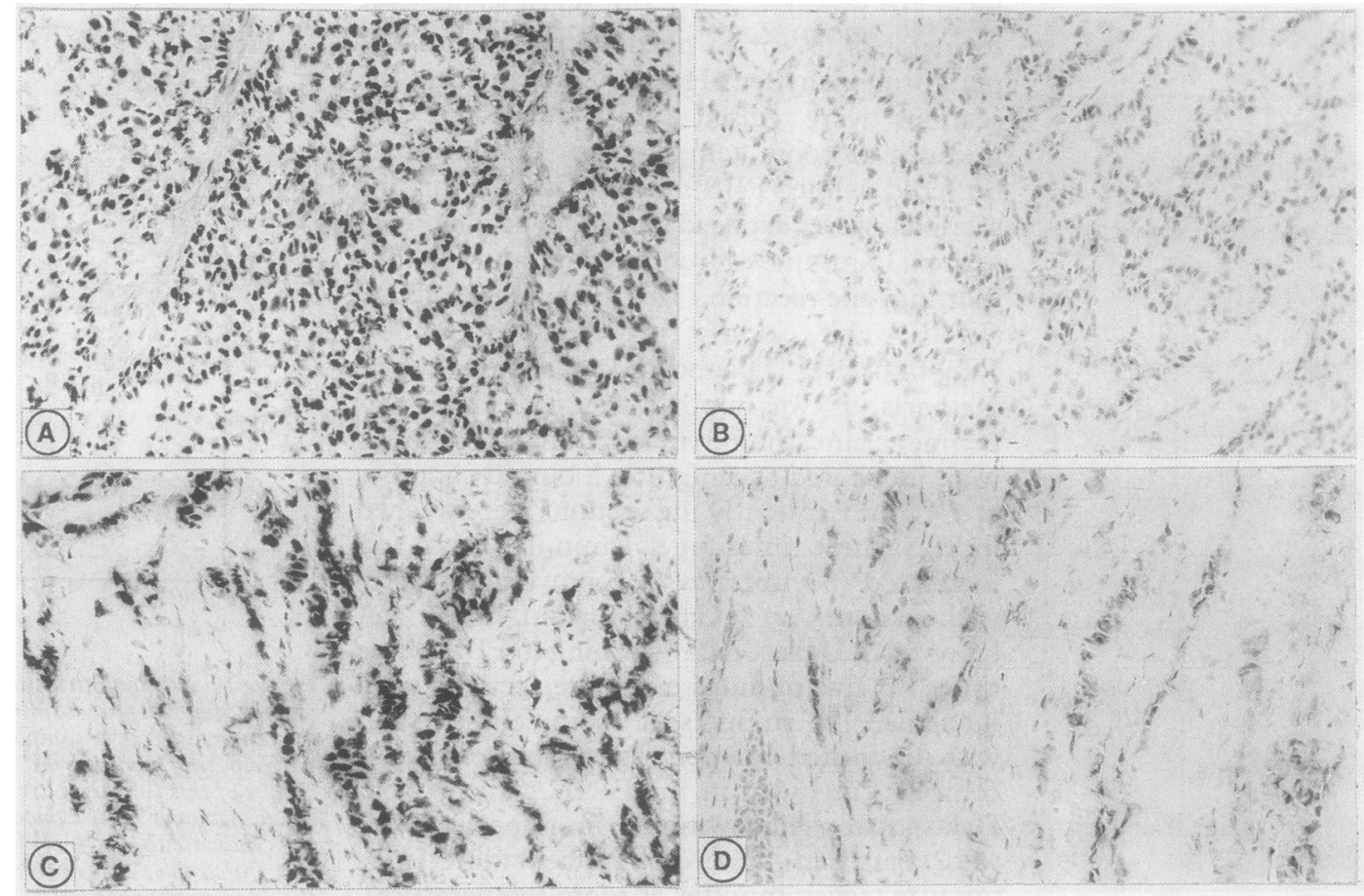


Figure 3

Semiquantitative immunohistochemical

scoring of oestrogen

receptor staining in

human breast cancer

samples, distributed to 20

participating laboratories.

Scores of this second trial

are presented as mean

and $(B)$ sample 3.

Participants 2, 5, 6, 8, 10,

$11,13,16,17,18$ and 19

used the Abbott protocol,

participant 15 its own

procedure, the others

applied the Maastricht

protocol. cryostat sections from two

$(S D)$ score. $(A)$ sample 2

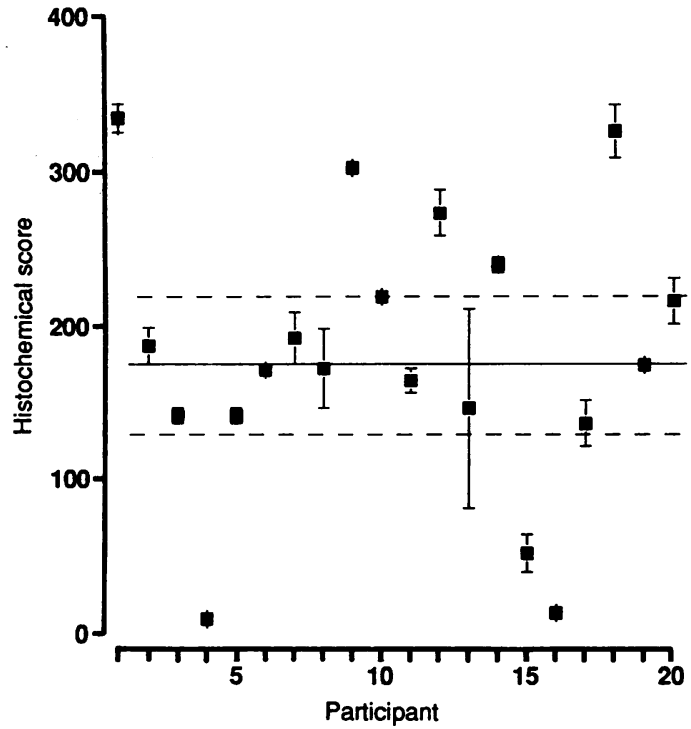

samples 2 and 3 were correctly classified as oestrogen receptor positive by $18(90 \%)$ of the 20 laboratories by obtaining a histochemical score of more than 35. A quantitative classification based on a histochemical score within $95 \%$ confidence interval limits was provided by $40 \%$ and $60 \%$ of the participants for samples 2 and 3 , respectively. To test the hypothesis that deterioration of oestrogen receptor immunoreactivity over time might have influenced the results, the participating laboratories were asked to supply the date that the sections were stained, which allowed us to calculate the elapsed time interval. In fig 4 the histochemical scores are plotted against time. It is clear that there is no correlation between immunostaining and time interval.

\section{Discussion}

Our results clearly indicate that the chosen approach, circulation of the freeze dried cryostat sections by normal post is adequate, given the fact that immunoreactivity did not deteriorate over time. A problem with the circulation of tissue sections obtained from a block of (tumour) tissue is that tissue samples might be heterogeneous, which may lead to differences among laboratories because of biological variation rather than technical inadequacies. This problem can be overcome by monitoring the composition of the tissue sample by examining sections at regular intervals. It does, however, limit the number of laboratories which might be included in a single quality control programme, probably not more than 50 and optimally, about 25 .

To perform an interlaboratry quality control

Table 2 Tumour classification (second test)

\begin{tabular}{lllll}
\hline & & \multicolumn{3}{c}{ Quantitative } \\
\cline { 2 - 5 } Sample & Correct & Incorrect & Correct & Incorrect \\
\hline 2 & 8 & 12 & 18 & 2 \\
3 & 12 & 8 & 18 & 2 \\
\hline
\end{tabular}

ॠ Within $95 \%$ confidence interval.

†Histochemical score of more than 35 .

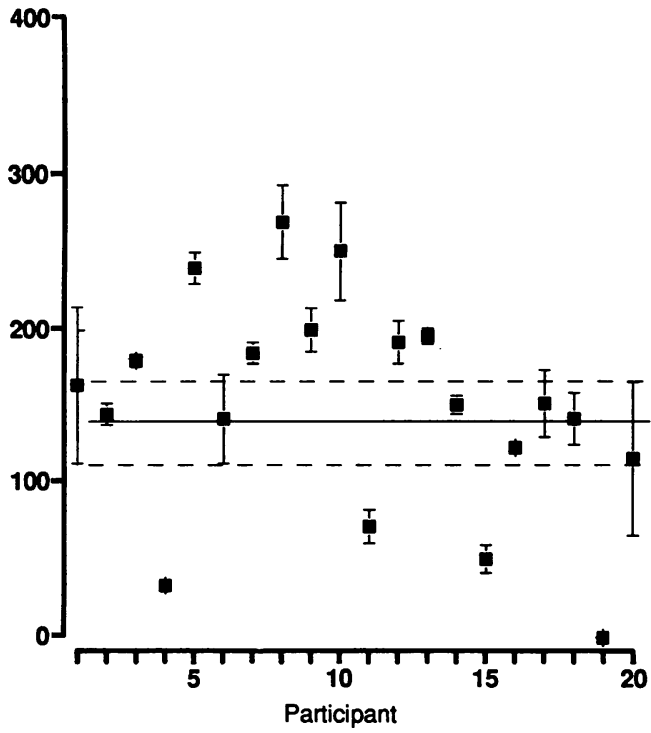

study on receptor immunocytochemistry a reliable scoring procedure for the immunoreaction should be established. Several approaches have been described for the semiquantitative evaluation of the receptor staining, such as the assessment of the percentage of positive cells, ${ }^{12-20}$ classification of varying numbers of staining categories, ${ }^{15-21}$ and various ways of mathematical analysis. ${ }^{1516-21}$ For this study we chose a quantitation method based on counting a fixed number of cells, classified according to staining intensity, which resulted in low intra- and interobserver variabilities. ${ }^{15} 1622$

Our results show that very significant differences exist among laboratories in the results of the immunocytochemical oestrogen receptor assay. Comparison of the stained sections (fig 2) shows that this is largely due to variability in staining intensity and not to differences in the semiquantitative evaluation as reflected in the histochemical score.

The interlaboratory variability does not seem to be attributable to the choice of technique: no significant differences were found

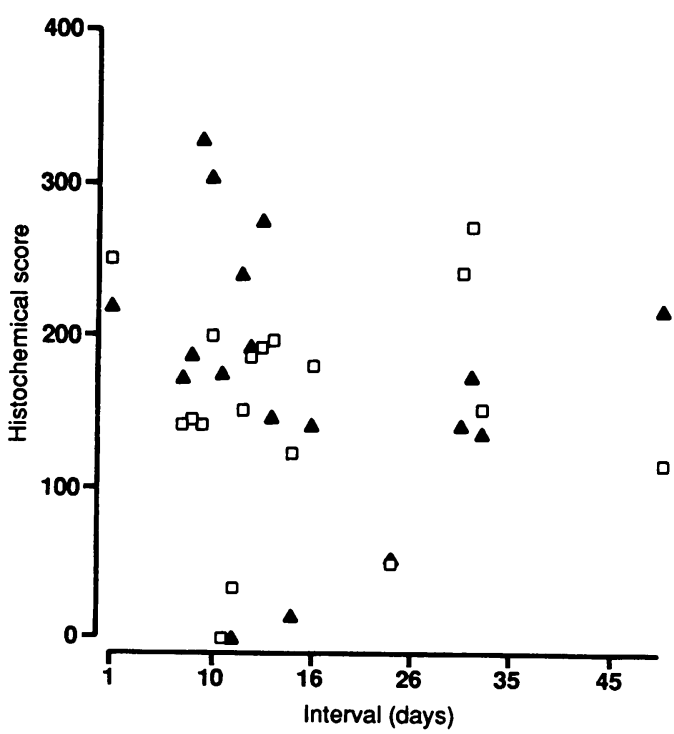

Figure 4 Semiquantitative immunohistochemical scoring of oestrogen receptor staining as a function of time interval between sectioning and staining.

$\square$ sample $2 ; \Delta$ sample 4 . 
between the two main staining protocols used. In terms of overall assignment of the tumours to oestrogen receptor positive or negative categories a fair score was reached (correct assignment in $100 \%$ for oestrogen receptor negative and of $80 \%$ for oestrogen receptor positive samples). In terms of the quantitative evaluation, however, only $40 \%$ and $60 \%$, respectively of the oestrogen receptor positive samples were rated within a $95 \%$ confidence interval.

Our results lead to the following conclusions: 1 Circulation of freeze dried sections is an adequate approach for the quality control of oestrogen receptor immunohistochemistry.

2 Semiquantitative scoring of immunocytochemical staining is valuable for performing correlative interlaboratory studies, although this scoring protocol may not be required for diagnosis or prognosis.

3 Significant interlaboratory variability exists, leading to a qualitatively correct oestrogen receptor classification in $100 \%$ negative but $80 \%$ in positive oestrogen receptor cases and quantitative agreement of only $45 \%$ (95\% confidence interval).

4 The perceived variability is not caused by systematic differences in the choice of the immunocytochemical technique.

5 Quality control programmes should be included in the standard procedures of every diagnostic immunohistochemistry laboratory.

We are much indebted to $\mathrm{Dr}$ Th Benraad and Mrs Anneke Ge are much indebted to Dr Th Benraad and Mrs Anneke Eeurts of the Laboratory for Experimental and Chemical Endocrinology, Sint Radboud Hospital, University of chemical oestrogen receptor assay on the two tumour cytosols used in the second trial.

We thank the pathologists who participated in the quality control programme. A Th Ariens, Sittard; M Beckers-Bloemkolk, Zaandam; B Beerends, Dordrecht; APR Blok, Den Haag $H$ Ebels, Groningen; S Hensen-Logmans, Rotterdam; $R$ van der Heul, Rotterdam; D Israel, Bergen op Zoom; J Koudstal Heul, Rotterdam; D Israel, Bergen op Zoom; J Koudstaal, Mooi, Amsterdam; J Peters, Breda; R Schapers, Venlo; W Mooi, Amsterdam; J Peters, Breda; R Schapers, Venlo; W Schoneman, Amsterdam; JW Steffelaar, Den Haag; P van der Valk and Dr C Meijer, Amsterdam; GP Vooijs, N
Vroom, Amsterdam; Sj S Wagenaar, Nieuwegein. Vroom, Amsterdam; Si S Wagenaar, Nieuwegein. This study was partly supported by grant N
The Netherlands Cancer Foundation KWF.

1 Elias JM, Gown AM, Nakamura RM, et al. Quality control in immunohistochemistry. Report of a workshop sponPathol 1989;92:836-43.

2 McGuire WL. Prognostic factors in primary breast cancer. Cancer Surveys 1986;5:527-36.

3 De Sombre ER. Breast cancer: hormone receptors, prognosis and therapy. Clin Oncol 1982;1:191-213.
4 Reiner A, Reiner G, Spona J, Schemper M, Holzner JH. Histopathologic characterization of human breast cancer in correlation with estrogen receptor status. A comparison of immunocytochemical and biochemical analysis. Cancer 1988;61:1149-54.

5 Howat JMT, Harris M, Swindell R, Barnes DM. The effect of oestrogen and progesterone receptors on recurrence and survival in patients with carcinoma of the breast. $\mathrm{Br} J$ Cancer 1985;51:263-8.

6 Koenders A, Thorpe SM. Standardization of steroid receptor assays in human breast cancer. Long-term within laboratory and between laboratory variation of estrogen and progesterone receptor assays. Eur J Cancer Clin Oncol and progesterone

7 Jordan VC, Zava DT, Eppenburger E et al. Reliability of steroid hormone receptor assays - an international study. Eur J Cancer Clin Oncol 1983;19:357-63.

8 De Goeij AFPM, Bosman FT, Berns EMJJ. Determination of steroid hormone dependency of tumours utilizing tissue sections. Survey of histochemical techniques and their application in surgical pathology. J Pathol 1986;149: 163-72.

9 McCarty KS Jr, Reintgen DS, Seigler HF. Cytochemistry of sex steroid receptors: a critique. Br $J$ Cancer Res Treat 1982;1:315-25.

10 Underwood JC. Oestrogen receptors in human breast cancer: a review of histopathological correlations and critique of histochemical methods. Diagn Histopathol 1983;6:1-22.

11 King WJ, Greene GL. Monoclonal antibodies localize oestrogen receptor in the nuclei of target cells. Nature 1984;307:745-7.

12 Heubner A, Beck T, Grill H-J, Pollow K. Comparison of immunocytochemical estrogen receptor assay, estrogen receptor enzyme immunoassay, and radioligand-labeled estrogen receptor assay in human breast cancer and estrogen receptor assay in human breast cancer
uterine tissue. Cancer Res 1986;46(suppl):4291S-5S.

13 Anderson J, Bentzen SM, Poulsen HS. Relationship between radioligand binding assay, immuno enzyme assay and immunohistochemical assay for estorgen receptors in human breast cancer and association with tumor differentiation. Eur J Cancer Clin Oncol 1988;24:377-84.

14 Stefanini M, De Martini C, Zamboni L. Fixation of ejaculated spermatozoa for electron microscopy. Nature 1967;216:173-4.

15 McCarty KS Jr, Miller LS, Cox EB, Konrath J, McCarty KS Sr. Estrogen receptor analyses. Correlation of biochemical and immunohistochemical methods using monoclonal antireceptor antibodies. Arch Pathol Lab Med clonal antireceptor

16 Scheres HME, De Goeij AFPM, Rousch MJM, et al. Estrogen receptor quantification in human breast cancer: radiochemical assay on cytosol and cryostat sections compared with semiquantitative immunocytochemical analysis. J Clin Pathol 1988;41:623-32.

17 EORTIC Breast Cancer Cooperative Group. Revision of the standards for assessement of hormone receptors in human breast cancer. Eur J Cancer 1980;16:1513-15.

18 King WJ, De Sombre ER, Jensen EV, Greene GL. Comparison of immunocytochemical and steroid-binding assays ison of immunocytochemical and steroid-binding assays for estrogen in

19 De Sombre ER, Thorpe SM, Rose C, et al. Prognostic usefulness of estrogen receptor immunocytochemical assays for human breast cancer. Cancer Res 1986;46 (suppl):4256S-64S

20 Giri DD, Dangerfield VJM, Lonsdale R, Rogers K, Underwood JCE. Immunohistology of oestrogen receptor and D5 antigen in breast cancer: correlation with oestrogen receptor content of adjacent cryostat sections assayed by radioligand binding and enzyme immunoassay. J Clin Pathol 1987;40:734-40.

22 Remmele W, Hildebrand U, Hienz HA, et al. Comparative histological, histochemical, immunohistochemical and
biochemical studies on oestrogen receptors, lectin recepbiochemical studies on oestrogen receptors, lectin recep-
tors, and Barr bodies in human breast cancer. Virchows Arch (Pathol Anat) 1986;409:127-47.

23 Snijders MP, De Goeij AF, Koudstaal J, et al. Is immunohistochemical analysis of oestrogen and progesterone receptors in endometrial carcinoma superior to the radioligand binding assay? J Pathol 1990;161:129-35. 